\title{
Commentary: Meta-Analyses Reporting the Prognostic Value of Androgen Receptor Splice Variant 7 in Castration-Resistant Prostate Cancer
}

\author{
Michael W. Kattan ${ }^{1 *}$ and Ronald M. Bukowski ${ }^{2}$ \\ ${ }^{1}$ Department of Quantitative Health Sciences in the Lerner Research Institute, Cleveland Clinic, Cleveland, $\mathrm{OH}$, \\ United States, ${ }^{2}$ Taussig Cancer Center, Cleveland Clinic, Cleveland, $\mathrm{OH}$, United States
}

\section{OPEN ACCESS}

Edited by:

Masaki Shiota

Kyushu University, Japan

Reviewed by:

Taku Naiki,

Nagoya City University, Japan

${ }^{*}$ Correspondence:

Michael W. Kattan

kattanm@ccf.org

Specialty section: This article was submitted to Genitourinary Oncology, a section of the journal

Frontiers in Oncology

Received: 04 September 2020 Accepted: 07 October 2020 Published: 30 November 2020

Citation:

Kattan MW and Bukowski RM (2020) Commentary: Meta-Analyses

Reporting the Prognostic Value of Androgen Receptor Splice Variant 7 in Castration-Resistant Prostate Cancer.

Front. Oncol. 10:602992.

doi: 10.3389/fonc.2020.602992
Keywords: prostate cancer, randrogen receptor, splice variant 7, castration-resistant prostate cancer (CRPC), prognostication

\section{A Commentary on}

Prognostic Value of Androgen Receptor Splice Variant 7 in the Treatment of Metastatic Castration-Resistant Prostate Cancer: A Systematic Review and Meta-Analysis

By Wang J, Zhang Y, Wei C, Gao X, Yuan P, Gan J, et al. (2020). Front. Oncol. 10:562504. doi: 10.3389/fonc.2020.562504

The Prognostic Value of Androgen Receptor Splice Variant 7 in Castration-Resistant Prostate Cancer Treated With Novel Hormonal Therapy or Chemotherapy: A Systematic Review and Meta-analysis

By Wang Z, Shen H, Ma N, Li Q, Mao Y, Wang C, et al. (2020). Front. Oncol. 10:572590. doi: $10.3389 /$ fonc. 2020.572590

\section{INTRODUCTION}

The concurrent systematic reviews recently published in Frontiers in Oncology by Zhize Wang et al. (1) and Jiaxin Wang et al. (2) provide a very similar report on the prognostic value of the androgen receptor splice variant 7 (AR-V7) in castration-resistant prostate cancer. As these might appear, at first glance, to be nearly identical, we believed it was pertinent to herein highlight the differences and summarize the findings. 
TABLE 1 | Characteristics of the Systematic Reviews by Z. Wang et al. and J. Wang et al.

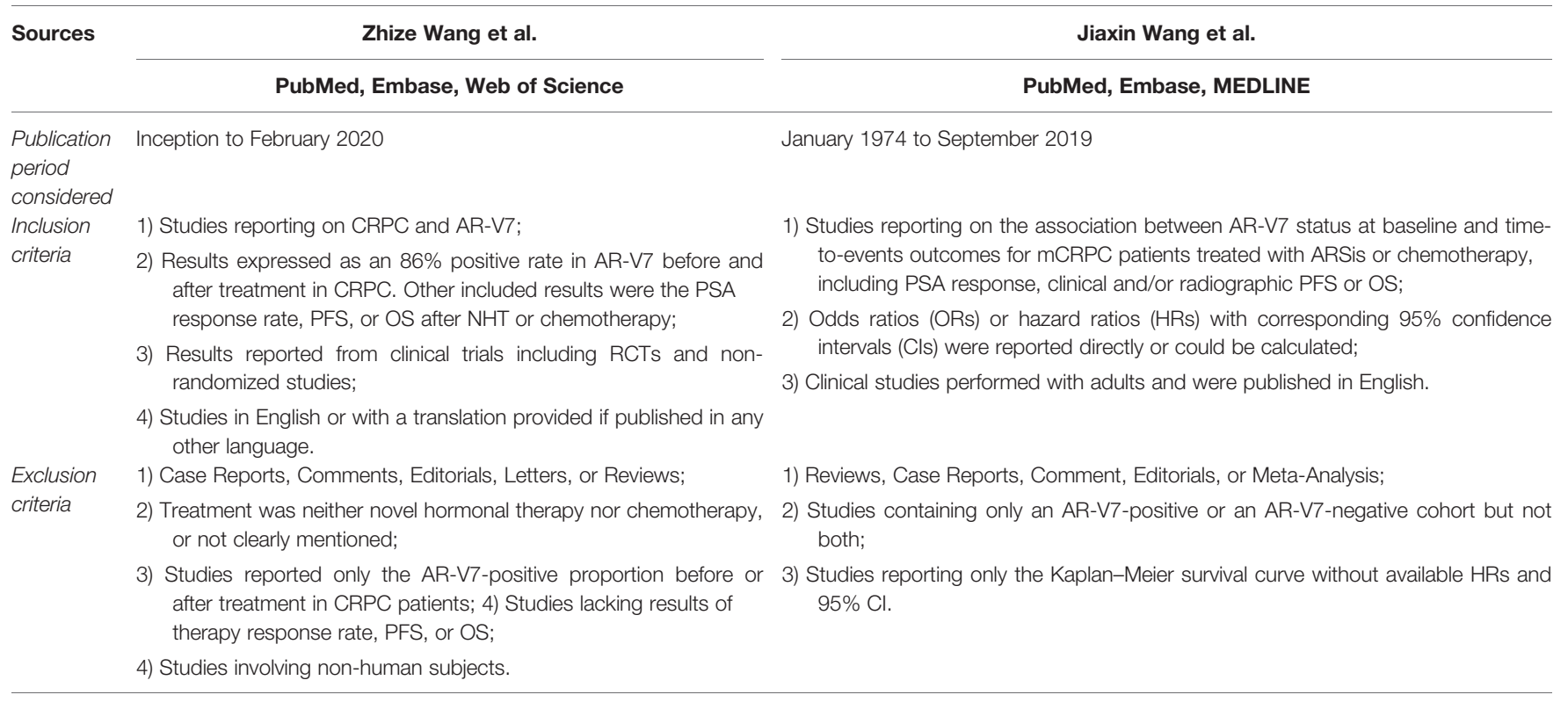

\section{Selection Criteria for the Meta-Analyses}

The paper by Z. Wang examined studies published on PubMed, Embase, and the Web of Science from inception to February 2020, while J. Wang restricted their search to PubMed, Embase, and MEDLINE from January 1974 to September 2019. More importantly, the paper by J. Wang studied metastatic castrationresistant prostate cancer, while $\mathrm{Z}$. Wang et al. looked only at castration-resistant prostate cancer. In addition, if patients were not receiving chemotherapy, J. Wang required patients to be treated by androgen receptor signaling inhibitors (ARSIs) or chemotherapy, while Z. Wang included only results from patients treated with novel hormonal therapy (NHT). For these reasons (Table 1), and perhaps others, the numbers of studies included for analysis differed: 21 in the J. Wang study and 36 in the Z. Wang study. Having said that, notable overlap exists between the studies included by each.

\section{STATISTICAL ANALYSIS}

Both of these PROSPERO-registered systematic reviews used nearly identical and customary, meta-analytic approaches. While different software packages were used, this should hopefully have no impact on the results. Z. Wang decided whether to use fixed vs. random effects models based on the $\mathrm{I}^{2}$ value, while J. Wang used exclusively random effects models. Both models have pros and cons (3).

\section{REPORTING OF RESULTS}

Both studies looked at overall survival, progression-free survival, and prostate specific antigen (PSA) response after chemotherapy.
However, Z. Wang also looked at AR-V7 positivity before and after treatment, while J. Wang furthermore subdivided results by method of detection.

\section{FINDINGS}

Not surprising-though reassuringly, given the overlap between the two meta-analysis-the findings between the two studies were quite similar: AR-V7-positive patients have worse prognosis, a trend that held regardless of treatment and endpoint. The hazard ratios for progression-free survival and overall survival were fairly similar (again, unsurprisingly, considering the included studies overlapped considerably). More difficult to reconcile were the odds ratios for PSA response. Z. Wang concluded that AR-V7-positive patients had a decreased PSA response rate (OR 0.13 for NHT, 0.63 for chemotherapy). J. Wang concluded AR-V7-positive patients had lower response rates (OR 6.01 for ARSIs, 2.23 for chemotherapy). Looking at the OR values, this would be a higher odds of response, rather than a lower, for the J. Wang study. It could be that J. Wang calculated the OR for AR-V7 negative, instead of positive, or that they calculated the OR for a non-response, rather than a PSA response. The fix to either is taking the reciprocal, which produces ORs of 0.17 and 0.45 , respectively, somewhat in line with those of the $Z$. Wang study.

\section{CONCLUSIONS}

Both studies argue for a prognostic role of AR-V7, with positive patients faring worse. The major limitation of 
studies like these is that they are not multivariable in nature. There are several prediction models available for men with progressive or hormone-refractory metastatic prostate cancer $(4,5)$. They use a variety of predictors and have reasonable accuracy. Thus, from the patient counseling perspective, one might want to know if AR-V7 positivity adds incremental value as a predictor, as this is the critical hurdle for any new biomarker (6). This is an important future research question.

\section{REFERENCES}

1. Wang Z, Shen H, Ma N, Li Q, Mao Y, Wang C, et al. The Prognostic Value of Androgen Receptor Splice Variant 7 in Castration-Resistant Prostate Cancer Treated with Novel Hormonal Therapy or Chemotherapy: A Systematic Review and Meta-analysis. Front Oncol. doi: 10.3389/fonc.2020.572590

2. Wang J, Zhang Y, Wei C, Gao X, Yuan P, Gan J, et al. Prognostic Value of Androgen Receptor Splice Variant 7 in the Treatment of Metastatic CastrationResistant Prostate Cancer: A Systematic Review and Meta-Analysis. Front Oncol. doi: 10.3389/fonc.2020.562504

3. Walker E, Hernandez AV, Kattan MW. Meta-analysis: Its strengths and limitations. Cleve Clin J Med (2008) 75(6):431-9. doi: 10.3949/ccjm. 75.6 .431

4. Smaletz O, Scher HI, Small EJ, Verbel DA, McMillan A, Regan K, et al. Nomogram for overall survival of patients with progressive metastatic prostate cancer after castration. J Clin Oncol (2002) 20(19):3972-82. doi: 10.1200/ JCO.2002.11.021

\section{AUTHOR CONTRIBUTIONS}

MK wrote this article. RB reviewed and advised on this piece. All authors contributed to the article and approved the submitted version.

\section{FUNDING}

Code DSC-08001617819PRD.

5. Halabi S, Small EJ, Kantoff PW, Kattan MW, Kaplan EB, Dawson NA, et al. Prognostic model for predicting survival in men with hormone-refractory metastatic prostate cancer. J Clin Oncol (2003) 21(7):1232-7. doi: 10.1200/JCO.2003.06.100. [published correction appears in J Clin Oncol. 2004 Aug 15;22(16):3434].

6. Kattan MW. Judging new markers by their ability to improve predictive accuracy. J Natl Cancer Inst (2003) 95(9):634-5. doi: 10.1093/jnci/95.9.634

Conflict of Interest: The authors declare that the research was conducted in the absence of any commercial or financial relationships that could be construed as a potential conflict of interest.

Copyright (c) 2020 Kattan and Bukowski. This is an open-access article distributed under the terms of the Creative Commons Attribution License (CC BY). The use, distribution or reproduction in other forums is permitted, provided the original author(s) and the copyright owner(s) are credited and that the original publication in this journal is cited, in accordance with accepted academic practice. No use, distribution or reproduction is permitted which does not comply with these terms. 